\title{
O PONTO E A ENCRUZILHADA: A POESIA NEGRA RASURANDO A LITERATURA OFICIAL ATRAVÉS DA INTERTEXTUALIDADE
}

Ivana Silva Freitas ${ }^{1}$

\begin{abstract}
Resumo: Este artigo, fruto da pesquisa realizada durante o doutorado, visa a análise de como a poética negra brasileira, através da intertextualidade, instaura pontos de rasuras e fraturas na memória, na história e na literatura oficial através do conflito e do reconhecimento do espaço poético como uma arena. A partir dessa análise, foi possível afirmar que a intertextualidade é uma constante discursiva da Literatura negra utilizada no sentido de rasurar o discurso hegemônico, instaurando o conflito, fazendo emergir outras memórias e histórias nas quais a população negra assume a condição de sujeito.

Palavras-chave: Poesia Negra. Intertextualidade. Memória. História. Literatura canônica.
\end{abstract}

\section{THE POINT AND CROSSROADS: THE BLACK POETRY INTRODUCING POINTS OF BLOTS AND FRACTURES IN MEMORY, HISTORY AND OFFICIAL}

\section{LITERATURE THROUGH INTERTEXTUALITY}

\begin{abstract}
This work, the result of research effected during doctorate studies, it aimed at analyzing how the Brazilian black poetic, through intertextuality, establishes points of blots and fractures in memory, history and official literature through conflict and recognition of the poetic space like an arena. According to this analysis, it has been possible state that intertextuality is a constant discourse of black literature used in order to erase the hegemonic discourse, establishing the conflict and giving rise to other memories and stories in which the black population assumes the condition of individual.

Keywords: Black Poetry. Intertextuality. Memory. History. Canonical literature.
\end{abstract}

\section{Introdução}

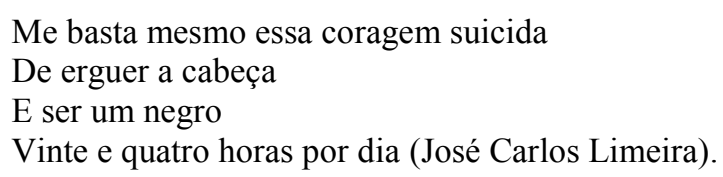

Diariamente, assim como no poema de Limeira, a minha identidade, sobretudo racial e de gênro, compõe minha realidade, minha vivência como leitora e obviamente como pesquisadora. Pesquisar sobre literatura é debruçar-se sobre representações de subjetividades e trabalhar com Literatura Negra é tangenciar as subjetividades que me representam. Por isso, orientar esta pesquisa a partir do meu desejo é uma "coragem suicida" de quem reconhece

1 Professora de Língua Portuguesa do Instituto Federal da Bahia (IFBA). Integrante do Programa Direito e Relações Raciais, da Universidade Federal da Bahia (PDRR/UFBA), Salvador. Doutora em Literatura e Cultura pela UFBA. E-mail: ivana.letras@yahoo.com.br. 
sujeitos no objeto de pesquisa. O meu cotidiano político, subjetivo, afetivo e acadêmico é nutrido pela incessante busca de me aproximar e aproximar a pesquisa que desenvolvo do conceito de "intelectual negro insurgente", cunhado por Cornel West (1999), na medida em que procuro seguir as orientações de não me desvincular da comunidade a qual pertenço, bem como busco prestar os meus conhecimentos e os resultados de minha pesquisa a essa comunidade a qual permaneço vinculada, ao mesmo tempo que dessa comunidade recebo suporte e contribuições em um processo interminável de trocas. Cumpre salientar como a minha formação no que concerne à discussão das relações raciais e à Literatura Negra foi iniciada no interior dos Movimentos Negros e não na Universidade, já que este espaço acadêmico, sobretudo durante o meu curso de graduação, limitou-se a reproduzir saberes instituídos, ao passo em que invisibilizou possibilidades fecundas de abordagens e produções poéticas de grupos minoritários.

Contudo, segundo West (1999), a manutenção dos vínculos e diálogos do intelectual com as comunidades as quais pertence não é o único nem o principal critério para caracterizálo no plano da insurgência. Antes e mais importante do que isto, está o permanente objetivo de questionar os "regimes de verdade" ${ }^{2}$ da sociedade, propondo, estimulando e acelerando o processo de confronto, rasuras e de alternativas práticas que possam auxiliar na construção de uma insurgência negra, seja no plano político, epistemológico ou acadêmico. Dessa forma, a proposta de levantar e analisar poemas negros, que através da intertextualidade proponham a rasura da literatura oficial, é uma tentativa, entre outras atividades, de me manter vinculada e dar um retorno à comunidade negra da qual faço parte e, sobretudo, questionar os "regimes de verdade", expor suas fraturas, instaurar e oferecer visibilidade aos processos de disputas e propor alternativas práticas de construção de uma insurgência negra.

Sendo assim, em diálogo com o texto O ponto e a linha. História do Direito e Direito positivo na formação do jurista do nosso tempo de Paolo Grossi, mas estabelecendo a rasura da linha para a inserção da ideia de encruzilhada, foi que escolhemos o título deste trabalho. Grossi salienta como a comparação tem o poder de relativizar o presente colocando-o em uma

2 Segundo Foucault “[...] a verdade não existe fora do poder ou sem poder [...]. A verdade é deste mundo; ela é produzida nele graças a múltiplas coerções e nele produz efeitos regulamentados de poder. Cada sociedade tem seu regime de verdade, 'sua política geral' de verdade: isto é, os tipos de discurso que ela acolhe e faz funcionar como verdadeiros; os mecanismos e as instâncias que permitem distinguir os enunciados verdadeiros dos falsos, a maneira como se sanciona uns e outros; as técnicas e os procedimentos que são valorizados para a obtenção da verdade; o estatuto daqueles que têm o encargo de dizer o que funciona como verdadeiro" (FOUCAULT, 2005, p. 11-12). 
posição dialética com outros momentos. Segundo o estudioso, através deste movimento é possível enriquecer o presente "[...] inserindo-o na linha que surge do passado, toca o presente e o sobrepassa, dirigindo-se, reta, em direção ao futuro" (2010, p. 14). Para Grossi, diferentes momentos históricos não podem ser compreendidos como "[...] ilhas separadas, mas pontos de uma longa linha" (2010, p. 15).

Não é novidade que a ideia de ponto nos remete tanto a concepção de algo em comum quanto a de seleção e delimitação dentre várias opções, ou seja, vários outros pontos. Uma outra analogia que também pode ser estabelecida é a do ponto no sentido de sutura, de costura de feridas que permaneciam abertas e que precisam estancar o sangue para a partir da cicatriz reabrir caminhos e compor encruzilhadas. A encruzilhada, por sua vez, parece-nos uma imagem mais fértil que a da linha. A encruzilhada é o local onde se cruzam caminhos a partir de um centro, um ponto em comum; por isso ela sugere a pausa, a reflexão seguida de uma quebra da zona de conforto para contemplar a necessidade de tomar decisões e seguir outros caminhos. Diferentemente da linha ou da reta, a encruzilhada reconhece os pontos em comum, o ponto de interseção, a cicatriz do encontro, mas os ultrapassa abrindo outros caminhos.

"O ponto" aqui é a intertextualidade, o que há em comum, ainda que como cicatriz, enquanto a encruzilhada representa o desconforto, a descontinuidade a rasura que possibilita a abertura de outros caminhos. "O ponto" também dialoga com os cantos sagrados da umbanda. Cantos que dialogam com a cultura de matriz africana, mas que já não são mais em iorubá. “O ponto", assim como na umbanda, é um exemplo perspicaz de sobrevivência e resistência do nosso legado africano, já adaptado às realidades atuais. Como não poderia ser diferente, a imagem da encruzilhada também é uma tentativa de estabelecer diálogo com as religiões de matriz africana ao ser remetida ao arquétipo de Exu, orixá que cuida da comunicação e dos caminhos. A proposta desse trabalho também representa as escolhas nas "encruzilhadas" das múltiplas possibilidades de pesquisas e as inevitáveis decisões por determinados "pontos". Assim, este trabalho, na verdade, é fruto do desenvolvimento de pesquisas realizadas durante a graduação, o mestrado e o curso de doutorado.

Desse modo, o estudo dos pontos de intertexto da poética negra brasileira com a poesia oficial possui uma relevância significativa, uma vez que tentará levantar e problematizar os diálogos que a poesia negra brasileira mantém com a literatura oficial contribuindo não somente para a divulgação da literatura negra, mas também com o desenvolvimento de reflexões teóricas acerca da mencionada literatura. Com o objetivo de responder tais problemáticas, par- 
timos da seguinte hipótese: a intertextualidade é constantemente utilizada pela poesia negra brasileira com o objetivo de rasurar a memória, a história e a literatura reconhecida como oficial.

Para tanto, trabalharemos com textos poéticos, porém sem restringir períodos históricos ou autores no sentido de analisar um número significativo e mais abrangente possível de poesias negras que estabeleçam diálogo com a literatura oficial. Para a referida análise, será necessário lançar mão do perfil de poesia negra baseado em traços comuns, levantados por Damasceno (1988), Souza (2005), Fonseca (2006) e Duarte (2011), no plano estético como o ritmo, a musicalidade e o léxico de origem africana; e no plano ideológico como a presença explícita do eu-enunciador que se quer negro e se coloca como porta-voz de seu grupo. Ou seja, demonstrar o processo de "enegrecimento poético" e sua potencialidade políticoideológica e até mesmo educacional. Os poemas serão analisados através da análise ideoestética, priorizando os elementos estéticos que estão em consonância com o projeto ideológico da literatura negra.

\title{
1 Os poemas na arena: a intertextualidade paródica da poesia negra com a poesia canônica
}

\author{
Que o poema venha armado \\ E metralhe a sangue-frio \\ Palavras flamejantes de revoltas \\ Palavras prenhes de serras e punhais... (Oubi Inaê Kibuko).
}

Pensar no espaço poético como uma arena é reconhecer na palavra o poder de armas, armas que podem travar os mais diversos tipos de lutas, de guerras e de disputas. Essa arte do confronto é propiciada pelo poder de réplica e tréplica, de paródia e de paráfrase que são evidenciadas na poesia. A poesia, conforme sugerem os versos da epígrafe deste capítulo, pode ser "armas" em punho, que são engatilhadas com o objetivo de "metralhar" "palavras flamejantes de revoltas", emprenhando as palavras com punhais, com outras possibilidades, com outras memórias, com outras narrativas que possam entrar em confronto, questionar, parodiar, recontar o que já foi cristalizado por palavras historicamente legitimadas.

Nesse sentido, a poesia negra também pode ser analisada como um instrumento de luta contra o racismo, inclusive o racismo disseminado na própria literatura reconhecida como cânone no Brasil. Instiga a investigação dos pontos de rasuras e fraturas entre seu discurso e o 
discurso da memória oficial. Para tanto, é necessário analisar como a poesia negra desenvolve diálogos com a poesia que representa o discurso oficial ao buscar construir desestabilidades, disputas e conflitos. Segundo Pollak (1989), atualmente, pela emergência de estudos em saberes fronteiriços e transdisciplinares, há uma predileção dos pesquisadores por escolher objetos nos quais reside o conflito, a competição, a concorrência, a disputa e é seguindo essa tendência que este trabalho se delineará.

A estratégia de usar a poesia para questionar o seu próprio formato, a forma de produção transgredindo normas pré-estabelecidas e questionando modelos estéticos também é um recurso bastante utilizado, inclusive na literatura brasileira já reconhecida como cânone. Questionar a imposição ou repetição de um modelo para os versos também foi algo preponderantemente realizado pelos poetas modernistas. "Poética", de Manuel Bandeira, ficou bastante conhecido pelo seu caráter contestatório que através da metalinguagem propôs os versos livres e uma outra forma de lirismo como libertação:

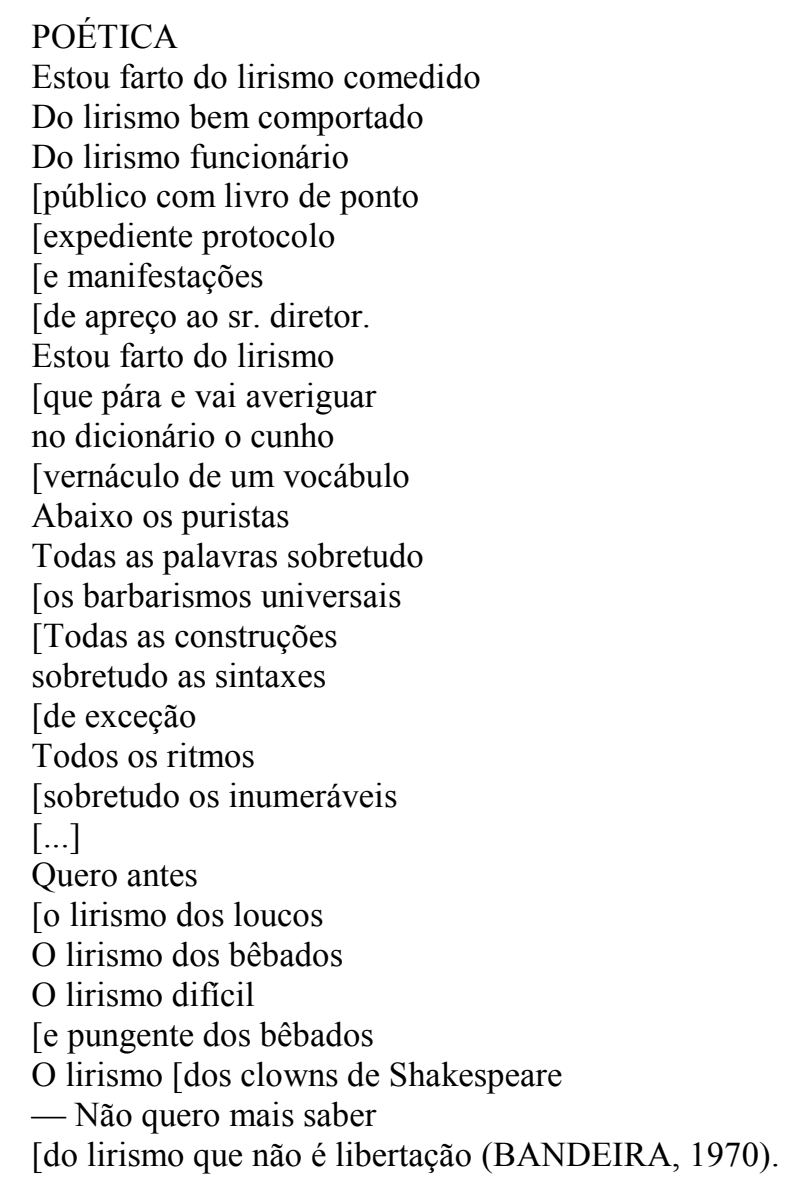

Já em "Lirismo a Brasileira" o foco se desloca das estratégias e recursos do fazer poético para as manifestações, estratégias e recursos do racismo na sociedade. Diferentemente da metalinguagem presente no poema de Bandeira, o poema de Andréia Lisboa vale-se dos neo- 
logismos para denunciar e questionar o racismo veiculado em uma espécie de "Lirismo à brasileira":

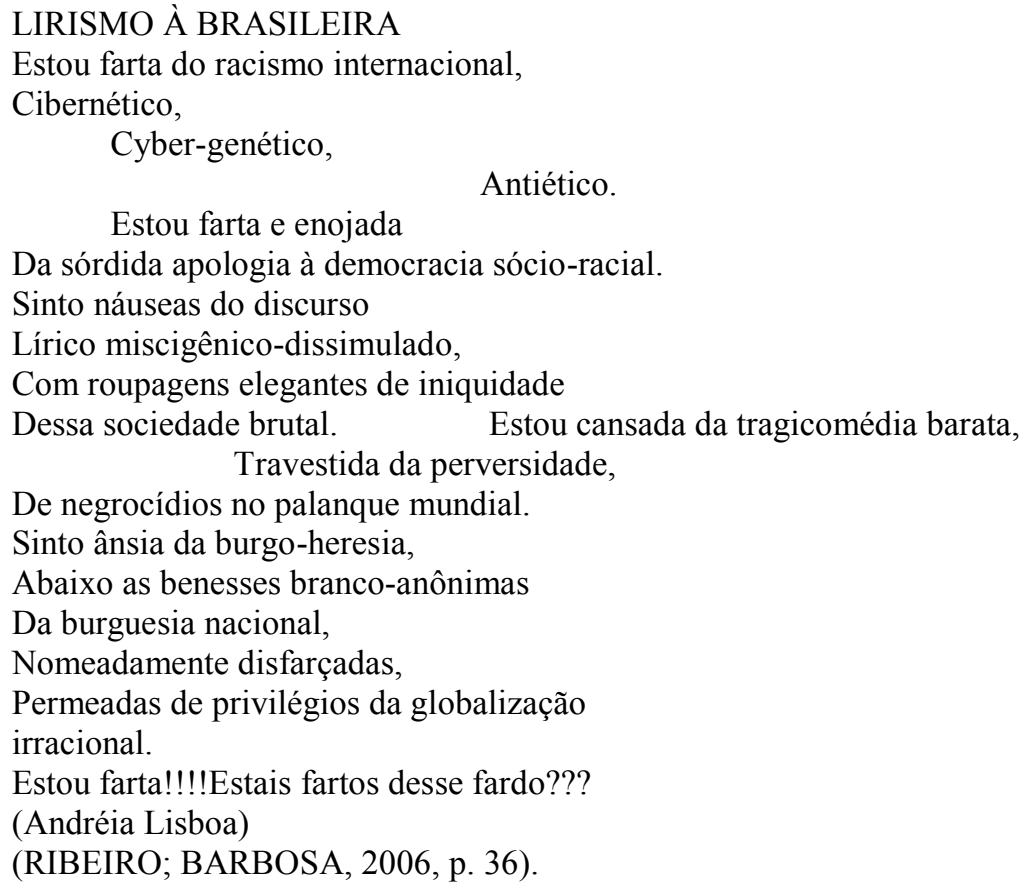

A ideia de libertação em "Lirismo à Brasileira" se aproxima mais do "lugar comum" associado à discriminação com base em um determinado pertencimento racial. Neste caso, a proposta não é apenas de emancipação e libertação dos versos em uma perspectiva estética que se reduz a imposição de métricas e rimas regulares, mas também de uma produção poética que ainda reproduz um padrão estético e cultural em consonância com a norma somática dominante. Consequentemente, a libertação sugerida no texto poético de Andréia Lisboa não se reduz aos versos, mas é estendida a libertação de uma sociedade com padrões historicamente racistas. No próprio título, a expressão "à brasileira" pode nos remeter ao racismo à brasileira ${ }^{3}$. Juntamente com a mudança temática há a mudança de gênero do eu poético: "Estou farta", "Estou farto".

Entretanto, indubitavelmente, o tom de manifesto de "Poética" permanece em "Lirismo à Brasileira”. A ideia de protesto, discordância de uma prática social, permeia os dois poemas sendo que, mais uma vez, o poema negro estende sua denúncia ao não se limitar a fadiga de

\footnotetext{
3 Segundo Munanga (1999), o preconceito velado típico do racismo à brasileira - menos explícito que nos Estados Unidos - prejudica o processo de formação de consciência e mobilização da própria vítima; e para Moore (2007), que define o modelo de relações raciais na América Latina como pigmentocrático e clientelista, essa ordem racial pigmentocrática corresponde a consequência da política consciente de mestiçagem.
} 
um único indivíduo na medida em que encerra-abrindo um possível diálogo com o leitor: “Estou farta!!!! Estais fartos desse fardo???”. Já o trocadilho entre lirismo e racismo faz uma analogia de quanto o lirismo reconhecido como cânone no Brasil ainda mantém estreitas relações com o racismo. Na maioria das vezes, como a expressão "à brasileira" sugere, esse racismo representado e reiteradamente disseminado através da literatura canônica se configura por uma perspectiva escamoteada, muitas vezes dúbia de uma produção que se intitula muito mais nacionalista do que racista ao buscar representar as três raças formadoras do Brasil pela perspectiva da mestiçagem e do mito de democracia racial. Pesquisador com afinco das relações raciais no Brasil, Kabenguele Munanga, assim como Abdias do Nascimento, coloca tais práticas no plano do genocídio. Ou seja, a miscigenação ao contrário do que pode se pensar, não aproxima nem tampouco iguala os brasileiros de diferentes origens raciais. Pelo contrário, a miscigenação diferencia e, sobretudo hierarquiza, criando o que Moore (2007) caracteriza como uma "ordem pigmentocrática". Nesse sentido, cabe ainda ressaltar outra problemática que emerge da política de miscigenação no Brasil. O fato de vivermos em um país essencialmente multirracial levanta também a impressão de que as três raças formadoras do Brasil vivem em plena harmonia. Contudo, segundo Gomes, "A democracia racial é uma corrente ideológica que pretende eliminar as distinções entre as "três raças" formadoras da sociedade brasileira (a negra, a índia e a branca), afirmando que existe entre elas união e igualdade" (1995, p. 61). Na verdade, a democracia racial compôs uma espécie de mito com objetivo de ocultar o pensamento racista brasileiro e deslegitimar a organização da luta antirracista.

Com o objetivo de explorar o diálogo entre os poemas e estender a reflexão a respeito de como a literatura negra pode parodiar textos canônicos e construir outras imagens da mulher negra destaca-se também o poema de Márcio Barbosa que constrói uma intertextualidade com um poema de Manuel Bandeira:

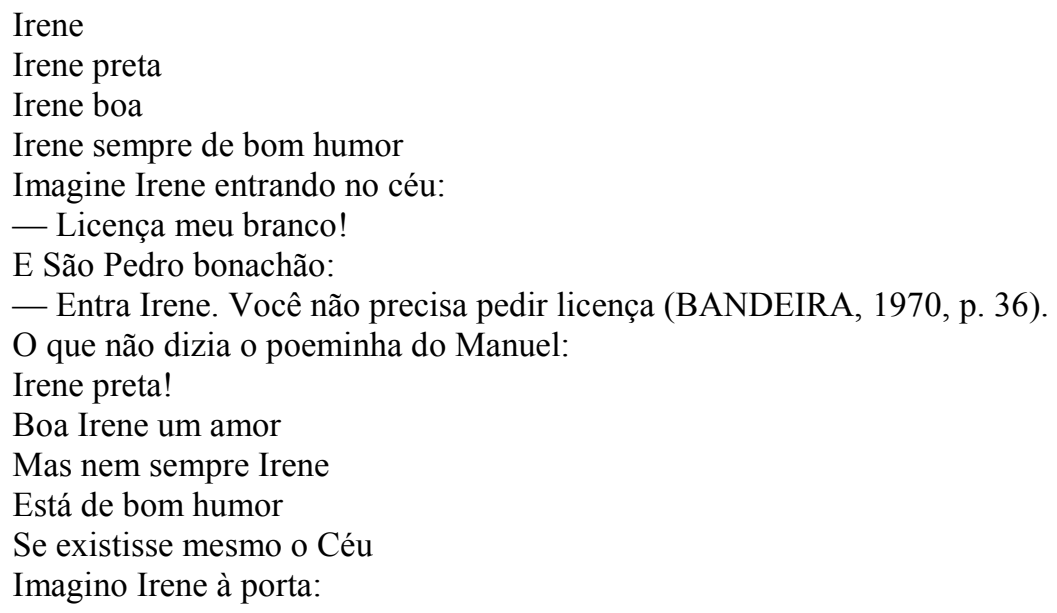




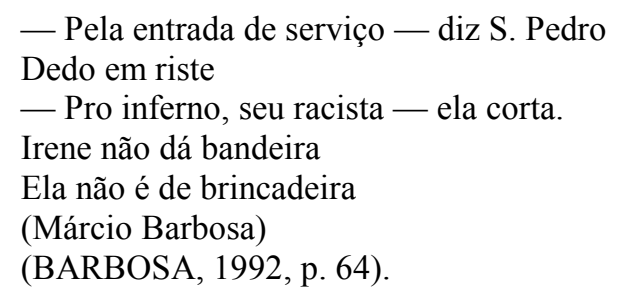

A professora e pesquisadora Heloisa Toller Gomes caracteriza a produção literária de Márcio Barbosa como "dizer diversificado" pelo seu caráter ornamental permeado de inovações verbais e experimentalismos gráficos. Ao analisar especificamente "O que não dizia o poeminha do Manuel”, a estudiosa ressalta a apropriação do poema de Manuel Bandeira através do que chama de "humor nada inocente", "leitura dupla, em superposição" e "uso atilado das brechas e dos silêncios da literatura canônica". (2011, p. 308). Ainda é possível reiterar a conexão que Gomes realiza entre o rompimento com a literatura canônica e a descoberta de uma ancestralidade africana "[...] o que propulsiona a libertação das amarras e possibilita a criação de uma literatura cujo sustentáculo seja ela mesma, não a imitação do opressor." (2011, p. 306).

O uso do silêncio da literatura canônica na construção de uma produção poética autônoma fica evidente no texto poético em análise, estabelecendo um jogo paródico, reinventando usos da linguagem e propondo uma espécie de revisão através da reescrita literária. O texto de Márcio Barbosa já se coloca em descontinuidade em relação ao texto anterior desde o título. "O que não dizia o poeminha do Manuel” já sugere que o poema de Manuel Bandeira silenciou algo que agora se pretende "corrigir". Outras questões que também explicitam o tom questionador carregado de ironia ainda no título são o uso da palavra poema no diminutivo, "poeminha", e a referência ao autor do texto antecessor através apenas do primeiro nome "Manuel". Diferente do que recomenda a tradição acadêmica, o autor canônico não foi citado através do sobrenome. Pelo contrário, quando a palavra "bandeira", mesma que dá sobrenome ao autor, aparece no texto é com um caráter polissêmico que se aproxima mais da ideia negativa de "dar bandeira", "cometer falhas e equívocos". O distanciamento também é realizado entre Irene e o autor do poema "Irene", ela "não dá bandeira".

Reafirma-se no poema de Márcio Barbosa as qualidades de Irene, mas questiona-se a ideia de eterna alegria e conformidade que está ligada a uma suposta infantilidade e passividade: "nem sempre Irene está de bom humor". Na sequência, o "racismo à brasileira", camuflado por uma suposta homenagem à Irene é questionado quando Irene chama São Pedro explicitamente de racista. Nessa lógica, vale ressaltar como até a ideia de céu é questionada: “Se 
existisse mesmo o Céu". Tal questionamento está em consonância com a filosofia do segmento cultural africano iorubano segundo o qual os Eguns, espíritos dos mortos, habitam o Òrun, espaço abstrato, ao invés de céu. Essa perspectiva é representada ainda com maior afinco em um terceiro poema que constrói um diálogo com os dois textos anteriores:

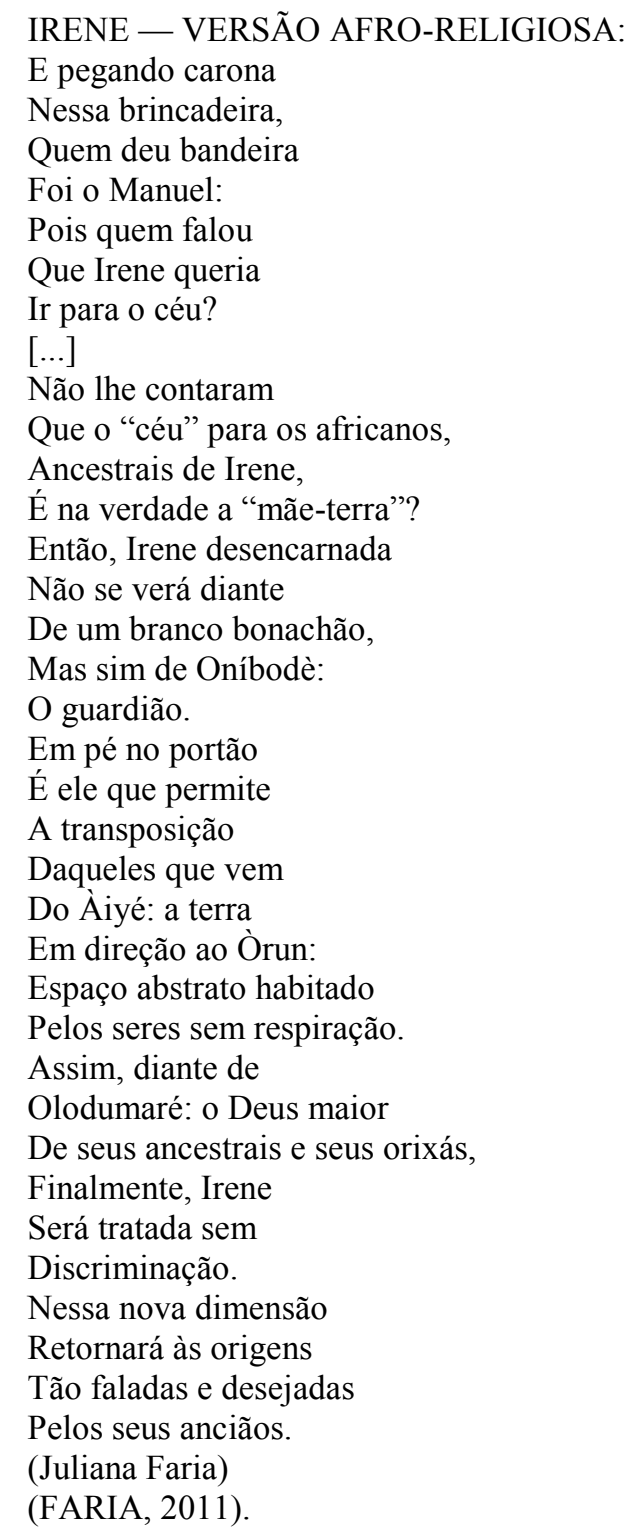

O poema de Juliana Faria propõe uma "outra versão" de Irene, uma versão afroreligiosa. O próprio exercício de se afirmar como "versão" ao mesmo tempo em que delimita seu afastamento de alguma outra versão "reconhece" que há outras versões possíveis. Tal prática está em consonância com a discussão de postulados teóricos que tem buscado na contemporaneidade rever posturas cristalizadas, rigidez e fixidez para a valorização da ideia de trânsito, entre-lugar e multiplicidade de narrativas e interpretações. De tal modo, afirmando que está "pegando carona" no que chama de "brincadeira", o poema se desenvolve dentro do 
prisma religioso. Neste caso não há uma simples negação da existência do Céu como no poema de Márcio Barbosa, mas a interrogação de se Irene queria ir para o céu.

A representação de uma versão afro-religiosa para o poema de Manuel Bandeira apresenta outras possibilidades para Irene que não referendam a perspectiva judaico-cristã para se aproximar de uma perspectiva das religiões de matrizes africanas que, como é ressaltado pelo eu poético, são os "ancestrais de Irene". Divindades africanas, palavras em iorubá e a premissa de ancestralidade são elementos que compõem o poema e que lhe conferem a ideia de paródia, de descontinuidade, de rasura, de apresentação de outra memória que é colocada em disputa com a memória tida como oficial.

Esses discursos outros que retomam outras memórias, até então relegadas ao ostracismo, precisam ser trabalhadas em sala de aula, sobretudo na educação básica no sentido de oferecer aos educandos outras possibilidades. De acordo com Koch e Travaglia "todas as questões ligadas à intertextualidade influenciam tanto o processo de produção como o de compreensão de textos e apresentam consequências no trabalho pedagógico com o texto [...]" (1989, p. 95, grifo nosso). Essas outras versões se tornam ainda mais relevantes na prática pedagógica por dialogarem e ao mesmo tempo se afastarem do que é considerado cânone.

De acordo com Reis (1992) o próprio termo cânon vem da ideia de norma ou lei e, portanto estaria ligado ao poder e, sobretudo ao princípio de seleção, exclusão e consequentemente silenciamento. $\mathrm{O}$ estudioso ainda faz considerações sobre as questões de poder que envolvem os que selecionam e como essa seleção está comprometida com seus respectivos interesses, ou seja, de classe, cultura, etnia e etc. Por isso, Reis afirma que a literatura tem sido uma instituição que reitera fronteiras sociais e culturais perpetuando a exclusão de grupos étnicos, sexuais e etc. Enfim, a própria etimologia e concepção de cânone pressupõe exclusões e silenciamentos. Em contrapartida, a poesia Negra como contra-narrativa pressupõe o questionamento dessas exclusões e emergência de outras memórias, outras histórias, outras poesias e outras versões, inclusive afro-religiosas.

As possibilidades de reinvenções, releituras e emergência de outras versões, outras memórias e outros textos poéticos são práticas interessantemente factíveis através do recurso da intertextualidade. A intertextualidade permite, ou melhor, proporciona o exercício da paródia, de como diz o poema de Márcio Barbosa "da brincadeira", de silenciar o já dito para dar voz ao não-dito, de fazer emergir e ao mesmo tempo submergir, de confrontar, de lembrar e ao 
mesmo tempo esquecer, de instigar réplicas e tréplicas, paródias e paráfrases, intertextualidades explícitas e implícitas, temáticas e estruturais. As possibilidades de reinvenções, releituras e emergência de outras versões, outras memórias e outros textos poéticos são práticas interessantemente factíveis através do recurso da intertextualidade. A intertextualidade permite, ou melhor, proporciona o exercício da paródia, de como diz o poema de Márcio Barbosa "da brincadeira", de silenciar o já dito para dar voz ao não-dito, de fazer emergir e ao mesmo tempo submergir, de confrontar, de lembrar e ao mesmo tempo esquecer, de instigar réplicas e tréplicas, paródias e paráfrases, intertextualidades explícitas e implícitas, temáticas e estruturais. E nesse momento, quem entra "nos acréscimos" desse "jogo" de Irenes é o poema "Maria” de Adilson Augusto:

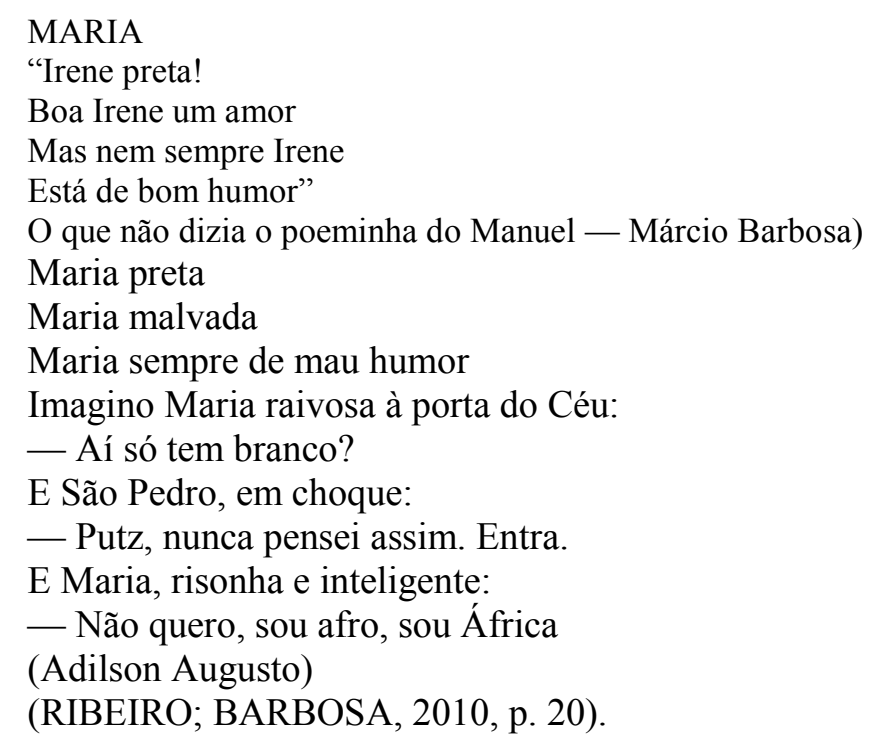

Partindo apenas do título do poema de Adilson Augusto, "Maria", não há referência ao poema "Irene" de Manuel Bandeira, ou seja, não ocorre um caso de intertextualidade explícita. Provavelmente devido a esse afastamento do título no diálogo, ocorre a estratégia da utilização da epígrafe que caracteriza a citação que atribui a intencionalidade do diálogo. Contudo, cumpre salientar, a epígrafe não é do poema "Irene", mas do poema "O que não dizia o poeminha do Manuel" o que confere uma estratégia de silenciamento do poema canônico, ao passo em que possibilita visibilidade, dialoga e respalda o poema de Márcio Barbosa. Ter como ponto de partida um poema negro ao invés de um já consagrado pela tradição canônica é subverter marcos, recriar modelos, repensar referências.

A própria mudança do nome não só do título, mas da personagem, ou seja, a substituição de "Irene" por "Maria" representa uma tentativa de se afastar ainda mais do poema antecessor e consequentemente conferir uma identidade ainda mais diversa, senão controversa a 
personagem que ainda continua sendo mulher, negra em um contexto de possibilidade de entrada em um cenário celestial. Mudar o nome é conferir outra identidade, estratégia semelhante à marca de Outra no poema "Outra negra Fulô". Neste caso, a tentativa de reversão se pretende ainda mais contundente que simplesmente marcar que se trata de uma "outra" "Irene", mas de outra personagem negra que não somente é descrita de forma evidentemente diferenciada, mas que nega a possibilidade de concessão da sua entrada no céu e se autodefine como afro/África. Não se pode também desprezar que não houve apenas a mudança do nome, mas a sutileza da escolha do novo nome revela um tom sarcástico, afinado com as intenções e estilos da paródia.

A associação do nome "Maria" com a personagem bíblica, a qual é comumente atribuída o prodígio de ter dado a luz ao menino Jesus, também pode ser salientada justamente com o objetivo de chamar a atenção da possibilidade da mãe de Jesus ser uma mulher negra e ao mesmo tempo ironizar o fato desta, devido sua identidade racial, estar de alguma forma excluída de um espaço de consagração da própria tradição que costuma a santificar.

Outra interpretação possível é da utilização do nome Maria como representação da mulher popular, da mulher por vezes "sem nome", fazendo referência a quando chamam qualquer mulher das classes populares de "Maria" em um processo de generalização que apaga as diferenças. O jogo de "contradição" opera tanto do ponto de vista estético quanto de conteúdo; o questionamento de narrativas consagradas, de contradizer e se colocar na contramão da tradição, ou seja, se afirmar como contra-narrativa. Contudo, o afastamento do discurso poético do poema "Irene" também ressona e destoa do discurso do poema de Márcio Barbosa. Esse afastamento ocorre de formas diferentes, é verdade, se revelando, por motivos ideo-estéticos, em maior proporção no caso do diálogo com o poema canônico do que com o poema negro.

Enquanto o poema de Bandeira afirma que Irene é preta, é boa e está sempre de bom humor; o de Barbosa além de afirmar que ela é preta, é boa, acrescenta que é um amor e faz a ressalva que nem sempre está de bom humor. Maria, apesar de ser preta, é malvada e está sempre de mau humor. Outra constante discursiva das paródias do poema de Bandeira, que não ocorre no texto de Adilson Augusto, é o questionamento da tradição judaico-cristã. No poema de Ju Faria o desejo de Irene de ir para o céu é negado e a própria ideia de céu é ressignificada pela "mãe-terra", inserindo e respaldando a tradição yorubá. Na tessitura dos versos de Márcio Barbosa essa ressignificação não é realizada para ser implementada apenas a negação da existência de céu: "se existisse mesmo céu". 
Em "Maria" a questão religiosa não é problematizada sob esse aspecto a não ser pela própria reafirmação da inexistência de brancos no céu, pela postura de Maria ou pelo personagem São Pedro que ganha diferentes conotações nos poemas em análise. $\mathrm{O}$ tom ou até mesmo a possibilidade de enunciação de São Pedro vai ganhando diferentes gradações nos diferentes poemas. No primeiro, São Pedro é o santo bondoso que se surpreende diante da subserviência de Irene e a concede uma condição privilegiada. Em "O que não dizia o poeminha do Manuel" São Pedro já é caracterizado com uma fala notoriamente de caráter racista, na medida em que exige que Irene entre pela porta de serviço.

Já em "Maria" a fala da personagem antecede a de São Pedro. Dessa forma, Maria ganha uma autonomia e uma postura mais questionadora do que Irene, do poema de Barbosa, que se revela mais reativa diante de uma postura racista. Maria antes de tudo questiona a inexistência de negros no céu e diante da suposta reflexão de São Pedro propõe uma possibilidade ao abdicar da sua concessão de entrada. Essa postura coloca à baila a importância da necessidade de pensar outras possibilidades de espaços, de ouvir outras vozes e construir narrativas outras ao invés de levantar concessões em instituições que permanecerão estruturalmente ainda vinculadoras e legitimadores de outra tradição. Outro aspecto também importante é a extrapolação da denúncia da existência do racismo para sugestão de alternativas para revertê-lo ou superá-lo.

Colocar os "poemas na arena" possibilitando condições igualitárias para o confronto é fazer emergir o direito à literatura, à escrita, é tomar posse da própria narrativa e não "tombar" antes de "lançar" a flecha que pode ter como alvo amores e dores, derrotas e vitórias, fugas e lares e a legitimação da produção de versos negros. Lançar os holofotes sobre produções literárias negras que revisam, reinventam, revertem e revisitam o fazer poético valorizado por uma tradição hegemônica é se posicionar na "trincheira" empunhando a arma da palavra e fazendo do espaço poético uma arena de saberes e vivências.

\section{Considerações finais}

Ofereço-te Exu

o ebó das minhas palavras

neste padê que te consagra

[...] Laroiê! (Abdias do Nascimento). 
O Ebó, oferenda dos rituais de religiões de matrizes africanas, é a representação e ao mesmo tempo a materialização mágica de um ato baseado na lógica da reciprocidade. Através do ebó, pede-se e simultaneamente oferece-se. Aproximar as palavras de um poema negro da imagem de um ebó constitui um exercício de aproximar-se das manifestações culturais de herança africana, mas, sobretudo, reconhecer nas palavras o poder "mágico" de representar e estabelecer reciprocidade com o interlocutor. Oferecê-las a Exu, orixá responsável pela comunicação, pelos caminhos e dono da encruzilhada, potencializa suas possibilidades, pedindo abertura de caminhos para os versos e também dedicando esses mesmos versos como oferenda.

$\mathrm{Na}$ encruzilhada, a poética negra brasileira critica, rasura, cobra a conta do dominador, mas, concomitante constrói propostas, alternativas, oferece caminhos. Em processo análogo a este, essas considerações finais, colocam esta pesquisa como o ponto de interseção entre questionar os "regimes de verdade", expor suas fraturas, instaurar e oferecer visibilidade aos processos de disputas, mas propondo alternativas práticas de construção de uma insurgência negra. Assim, o questionamento dos silenciamentos das vozes literárias que lutam para serem ouvidas foi operacionalizado através do confronto de textos poéticos historicamente consagrados e textos poéticos da literatura negra, reafirmando os pontos em comum e ao mesmo tempo abrindo caminhos outros através do ebó das palavras, fazendo do ponto de intertexto um ponto de partida para a construção da encruzilhada de vozes, literaturas, memórias, histórias, enfim, saberes.

Assim, como um dos principais saldos desta pesquisa, indica-se a intertextualidade da poesia negra brasileira com a memória, a história e a literatura oficial como um elemento que caracteriza a produção poética negra assim como outros traços já levantados por diversos teóricos, como a rejeição das políticas de branqueamento; a reversão do sentido pejorativo da palavra negro; o rompimento com os padrões consagrados; a construção de um elo com o continente africano e a emergência de um eu-enunciador que se quer negro e conta uma nova história da população negra brasileira. A instauração de outra ordem simbólica, na qual é possível a reversão de valores e hierarquias a partir da emergência de memórias, revisões da história e confrontos poéticos tanto no plano ideológico quanto no plano estético, foi aqui interpretada como a construção de uma especificidade política e ideológica que ultrapassa a de literaturas hegemônicas, na medida em que sua própria constituição como representação de minorias lhe confere esse papel de porta-voz de anseios da comunidade a qual pertence. 
A singularidade político-ideológica da poética negra brasileira também configurou-se relevante a partir das análises e cotejamentos de textos tornando possível a indicação da inclusão dos poemas para formulação de alternativas práticas no sentido de minimizar os desdobramentos do racismo no sistema educacional e auxiliar na implementação da Lei 10.639/03 que estabeleceu a obrigatoriedade do ensino acerca da História e Cultura Afro-brasileira, bem como Africanas nas instituições educacionais de ensino fundamental e médio, tanto públicas quanto privadas, tendo em vista a complexidade que constitui os desafios que comprometem a efetiva implementação desta lei.

A inclusão dos poemas negros em diálogo com poemas canônicos em livros didáticos de Língua Portuguesa pode proporcionar, através da literatura, a instauração de uma nova ordem simbólica e de disputa entre memórias que abrirão encruzilhadas de outros pensamentos e outras histórias indispensáveis para a implementação da referida lei. A insistência no material didático leva em consideração diversas variáveis como a minimização da permanência da construção de currículos paralelos e minoritários trazidos pontualmente por alguns docentes que buscam solitariamente implementar a Lei 10.639/03 e o desvio do equívoco da criação de uma disciplina específica ou da elaboração de materiais didáticos complementares sobre a cultura e a história negra quando esta temática deve ser abordada cotidianamente dentro das matérias e do currículo oficial.

A poética negra, através da intertextualidade, recorre ao quilombo de uma nova ordem simbólica que propõe a quebra dos elos das correntes do racismo. Para tanto, a inclusão, divulgação e reconhecimento dessas produções são indispensáveis. Contudo, a inclusão da poética negra brasileira não propõe a consequente exclusão dos textos poéticos com os quais dialoga pela perspectiva da rasura. Entretanto, é no mínimo razoável que ambas produções habitem os mesmos espaços, sem antagonismos, polarizações ou estabelecimento de hierarquias. Mas, lado a lado instaurando o conflito, expondo as fraturas, cozendo os retalhos, suturando, dando os pontos nas feridas.

Somente assim "O navio negreiro" de Solano Trindade poderá ancorar ou demonstrar para um público amplo rotas e "cargas" diferentes das do "Navio Negreiro" de Castro Alves. Será possível então que o "Exu" do poema de Abdias do Nascimento apareça não em oposição ao Jesus do "Auto da compadecida", e sim, ao lado. Ambos como alternativas possíveis. A partir do ponto de interseção, pretende-se abrir encruzilhada para que as negras Fulôs, os Macunaímas, as Irenes, os Sacis, as Bertolezas, Ritas Baianas, Josés e Mães-pretas comparti- 
lhem espaço com a "Outra Negra Fulô" (Oliveira Silveira), com a "Irene-Versão afroreligiosa" (Ju Faria), a "Maria" (Sacolinha), a "Minha mãe" (Luiz Gama), a Musa da Guiné (Luiz Gama), A preta Suzana (Maria Firmina dos Reis) e outras e outros mais que vierem no sentido de representar no texto literário a ginga das Nzingas, o heroísmo de Zumbi, a coragem das Teresas do Quariterê, a persistência de Samora Machel e Nelson Mandela, a ousadia das Zeferinas e das Luizas Mahin.

Dessa forma será possível, através do texto literário, retomar uma "Conversa com Cruz e Souza" (Luiz Silva Cuti), ver "Mahin amanhã" (Miriam Alves), conhecer "Dom Obá" (Luís Carlos de Oliveira - "Aseokaýnha"), ouvir "Vozes-mulheres" (Conceição Evaristo), dar “Outras notícias” (Éle Semog), lembrar que "Zumbi é senhor dos caminhos” (Jônatas Conceição), tirar do meio do caminho "Pedra, pau, espinho e grade" (Conceição Evaristo), questionar o "Discurso do crítico literário" (Proença Filho) e o "Lirismo à brasileira" (Andréia Lisboa) e falar "Ao pé do ouvido" (Jussara Santos) como quem reza baixinho o tecer da insurgência para entoar "Canto dos Palmares" (Solano Trindade) como um "Vento fortepoesia" (Lepê Correia).

Destarte, essas considerações que não são finais e sim encruzilhadas, dispõem minhas palavras como um padê, pedindo licença aos meus ancestrais, aos mais velhos, aos pioneiros e contemporâneos escritores e escritoras da literatura negra, assim como aos seus respectivos pesquisadores, às históricas instituições dos movimentos negros, para arriar os poemas-ebós oferecendo, em reciprocidade, o meu olhar aberto à crítica dos poetas citados e não citados, assim como dos pesquisadores e à todas e todos que vivenciam, se interessam e pesquisam com seriedade esta temática. Percorrendo algumas encruzilhadas, deixo marcado alguns pontos das interseções de mim e de outros que constroem os pontos da memória que não foi apagada, os pontos dados nas feridas empoeiradas das disputas travadas na arena poética e que demonstraram que a "rua reta não dá em nada". Sem pretensões conclusivas, essa pesquisa fica aqui como um: "Padê posto/Palavra arriada/Vida e verso/Nossa encruzilhada" (MACA, 2015, p. 2).

\section{Referências}

BANDEIRA, Manuel. Estrela da Vida Inteira: Poesias Reunidas. 2.ed. Rio de Janeiro: José Olympio, Instituto Nacional do Livro, 1970. 
BARBOSA, Márcio. O que não dizia o poeminha do Manuel. In: RIBEIRO, Esmeralda;

BARBOSA, Márcio (Org.). Cadernos Negros 15. São Paulo: Quilombhoje, 1992.

DAMASCENO, Benedita Gouveia. Poesia Negra no Modernismo Brasileiro. São Paulo: Pontes, 1988.

FARIA, Juliana. Irene-Versão afro-religiosa. Disponível em:

$<$ http://www.educarparaaigualdadeetnicoracial.ning.com>. Acesso em 8 dez. 2011.

FONSECA, Maria Nazareth. Literatura negra, literatura afro-brasileira:como responder à polêmica? In: SOUZA, Florentina; LIMA, Nazaré. Literatura afro-brasileira. Salvador: Centro de Estudos Afro-Orientais, 2006.

FOUCAULT, Michel. A ordem do discurso. São Paulo: Loyola, 2005.

GOMES, Heloisa Toller. Márcio Barbosa. In: DUARTE, Eduardo de Assis; FONSECA, Maria Nazareth Soares (Org.). Literatura e afrodescendência no Brasil: antologia crítica. Belo Horizonte: UFMG, 2011.

GOMES, Nilma Lino. A mulher negra que vi de perto. Belo Horizonte: Mazza Edições, 1995;

GROSSI, Paolo. O ponto e a linha. História do Direito e Direito Positivo na formação do jurista do nosso tempo (Introdução). In: Idem. O Direito entre o poder e o ordenamento. Tradução Arno Dal Ri Júnior. Belo Horizonte: Del Rey, 2010.

KOCH, Ingedore;TRAVAGLIA, Luiz Carlos. Texto e coerência. São Paulo, Cortez, 1989.

LISBOA, Andréia. Lirismo à brasileira. In: RIBEIRO, Esmeralda; BARBOSA, Márcio (Org.). Cadernos Negros 29. São Paulo: Quilombhoje, 2006.

MACA, Nelson. Gramática da Ira. Salvador: Editor Nelson Gonçalves, 2015.

MOORE, Carlos. Racismo e Sociedade: Novas Bases epistemológicas para entender o racismo. Belo Horizonte: Mazza Edições, 2007.

MUNANGA, Kabenguele. Rediscutindo a mestiçagem no Brasil: identidade nacional versus identidade negra. Petrópolis, RJ: Vozes, 1999.

NASCIMENTO, Abdias do. Padê de Exu Libertador. In: Axés do sangue e da esperança (orikis). Rio de Janeiro: Achiamé/RIOARTE, 1983, p. 9-14.

POLLAK, Michael. Memória, Esquecimento, Silêncio. Rio de Janeiro, Estudos Históricos, v. 2, n. 3, 1989.

REIS, Roberto. Cânon. In: JOBIM, José Luís (Org.). Palavras da crítica. Rio de Janeiro: Imago, 1992.

SOUZA, Florentina da Silva. Afro-descendência em Cadernos Negros e Jornal do MNU. Belo Horizonte: Autêntica, 2006.

WEST, Cornel. The dillema of the black intelectual. In: The Cornel West: reader. Basic Civitas Books, 1999.

Recebido em 14 de agosto de 2015.

Aceito em 20 de setembro de 2015. 
